\title{
Mass Customization Marketing Strategies for China Railway Freight
}

\section{Transportation Service}

\author{
Yuhua Guo \\ Bureau of Transportation, Ministry of Railways, Beijing 100844, China \\ $\mathrm{PhD}$ candidate of Central South University in railway transportation planning and management \\ E-mail: guoyuhua675@yahoo.cn
}

\begin{abstract}
Service marketing theory is used to study mass customization marketing strategy for China railway freight transport. This research puts forward that, identification and profitability are the requisitions; customization ability of production system, rapid delivery system in between production systems and external organizations, and information support systems are the critical issues to success. With these basis's, four important aspects are proposed to support mass customization for China railway freight transport: to identify and determine the customers who are supplied customized production, to form service differentiation through product design innovation and service process diversification, to realize railway production intensification, mass production and standardization operation, to provide quick information for customization marketing with informatization tochnologies.
\end{abstract}

Keywords: Railway freight transport, Mass customization marketing, Service marketing, Flexibility management

\section{Introduction}

According to PINE, B. J. II. (1993), mass customization is a marketing philosophy of improving customer satisfaction through supplying differentiated products or services with flexible service and rapid response, which requires customer's participation in product or service process. Mass Customization is also a scientific management concept different from mass production. In the traditional industrial age, standardized products or services can be produced in mass; while customized products or services can only be in a small amount. But in the information age, enterprises can meet the requirements of mass customization production. Mass customization marketing aims to help enterprises achieve economical efficiency by meeting wider scope of demands in more market segments, which is opposite from the traditional mass standardized production that gets scale economies by limiting and reducing customer's demand choices.

Mass customization marketing concept is deceived by the driving force behind the fierce market competition. As competition intensified, each manufacturer offering standardized products turned to reducing costs and improving quality and durability of their products, which causes high homogenization of products or greater difficult in product differentiation. While price war has become the disadvantageous option for both suppliers and demanders, how to better meet customer's needs becomes a new point of competition. Customization is to provide a specific product or service consistent to specific needs of customers. This means that the market is further divided, with an extreme situation of complete customization in which each buyer will become a distinguishable market segment.

What makes mass customization marketing a reality is the advanced modular production technology, telecommunications and information technology. For example, Toyota's JIT (Just In Time) production system is a representative of the flexible production system based on the modularization of its production factors. The flexible production system makes it possible for mass customization production, while the application and popularization of network technology greatly shorten the distance between manufacturers and customers. It helps customers to quickly and widely pass their specific demands to the production or service providers and mass supply becomes possible. According to Dresner, Martin \& Xu, Kefeng's (1995) research, the flexibility of service sector is similar to that of manufacture.

In the past, mass customization marketing made the greatest success in tangible products by producers, such as DELL Computer Corporation. In fact, when manufacturing industry has completely or close to zero inventories, their management model will be the same with that of the service business without inventory. Service business inherently has no inventory. They can make rapid and accurate response to customer's needs and preferences. During the peak season, they have sufficient capacity to meet demands and maintain the standard service levels; 
while in the low season, they can increase sales through marketing and management and improve the utilization rate of the fixed facilities and equipment. Therefore, to balance needs and demands and to predict and manage the demand as accurately as possible are the most challenging issues for service business.

Railway freight transport service is a typical production service business. The typical characteristic of the demand of service business is big cyclical fluctuation in demand and high time-demanding. However, the sale and the production of service product are undertaken in parallel. Therefore now it is very urgent and significant for China railway freight transport industry to study how to improve supply elasticity during periods of peak demands and attract more customers to increase utilization rate of facilities in slack business season. In this background, this paper studies the mass customization marketing strategy for China railway freight transport service, as well as its implementation premises and management models. The purpose of this research is to improve the customer satisfaction by improving customization standards, and finally to obtain higher and more stable customer demands.

\section{The key issues of mass customization marketing strategies for China railway freight transport service}

The first precondition of mass customization marketing strategy is market separability and profitability; followed by a high customization capability of the production system, namely, the production system flexibility; the third precondition is the rapid interactive capability of the production systems interactive with customers, multi-modal transport partners, as well as the end of logistics providers and other organizations; the final one is information support system(Don, P. Rogers, M. \& Dorf, B. ,1999).

\subsection{Complete identification and profitability of market}

The advent of customized supply age means the end of mass standardized production age. After World War II, mass standardized production capacity grew up exponentially, leading to excess supply. Then the suppliers launched intense competitions in the product quality, functionality and price, leading to lower and lower profit margins. On the other hand, due to the increased expenditure budget and personalized demand of buyers, there arose barriers in between supply and demand. This is because that mass standardized production obtains scale economies of the production in exchange for the sacrifice of more people's specific needs and shares it with customers through low-price sale. Nevertheless, when the attractiveness of low price could not resist the loss caused by reduced specific demand, the customized service will have become the new direction of competition.

Mainstreaming the needs of individual means "to deal with a product for all" concept is obsolete. Customers now want more customized service from providers, and are willing to pay the corresponding price. For suppliers, the first precondition of provision of customized product or service is to be able to clearly separate and identify the market. The market can be fully segmented, which means the ultimate goal is that each customer will be a market segment. In complete market segments, suppliers will provide customized services or products to each customer.

Even if the market can be fully segmented to each customer, the next biggest problem is to tell whether this model is worthy from the commercial assessment, that is, to choose a level of profitable customization (Fang, Xiaoping, Chen, Zhiya \& Li, Zhizhong, 2003). This is related to the nature of the markets faced by the manufacturer. Here, the size of an individual market segment needs to be analyzed. Specifically, the size can be divided into four related aspects: single transaction volume, whether there are continuous transaction needs, average annual transaction amount of a single customer and the total number of customers. In general, institutional client has a bigger transaction than individual customer does. Institutional client's purchased equipments and subsidiary technical services and personal consumer's durables are intermittent demands; while institutional client's need for raw materials, fuel, parts and technical maintenance services, and individual consumer's consumables are continuous demands. China railway freight transport sector mainly provide service for institutional client's goods transport and logistics demand, which is a large and continuous demand. As the institutional clients increase the level of cost control, there will be a tendency of smaller volumes and more batches.

\subsection{Customization capability of production system}

Flexible manufacturing system derives from Toyota's lean management. In order to adapt to a fast-changing market demands, Toyota developed a lean management system which combined the characteristics of manual production system (small-volume, multi-species, highly customized) and that of the mass production system (low cost, fast production). The lean management system overcomes the high cost of manual production system and the poor flexibility of mass production system at the same time. CAI Jian-Hua(2006), from the perspectives of resource integration, groups the flexibility of lean production system into four categories: resource-layer 
flexibility, capacity-layer flexibility, supply-layer flexibility and soft flexibility. He thinks that Toyota makes the organic integration of these flexible resources through Kanban method, which makes the lean production system demonstrate a market-oriented flexibility and be able to adapt to market competition.

The supply-layer flexibility of a market is expressed in supply chain flexibility. However, the manufacturing enterprise is just part of the supply chain. Toyota views that the root of all evil is the inventory in the traditional model. Here, the inventory includes not only the inventory in the manufacturing sector but also in the circulation areas. To make the whole supply chain with a high flexibility, supply chain integration is the most important in circulation areas, particularly for the transport companies, logistics companies and manufacturing enterprises. Therefore, China railway freight transport sector must innovate services (Guo Yuhua, 2006), and carry out logistics services(Wen, Kexue, Han, Boling,2004). The railway freight transport itself is a part of the supply chain. To improve its customer's supply chain flexibility is critical to satisfy its customers and acquire competitive advantage. It requires the railway production system to be able to increase the flexibility of its production system to adapt to such a low-volume and multi-batch transport demand trend. According to traditional concept, the railway is a large-scale, long-distance effective transport model, but now it faces the challenge which requires it to make strategic adjustments that it should use flexible production system to realize mass customization production in order to adapt to market development.

\subsection{Interface with customers and partners}

The whole supply chain flexibility is determined by of each node organization on this supply chain, including the flexibility of suppliers' suppliers, suppliers, logistics providers and retailers, as well as the coordination effectiveness of these organizations.

The new interactive system should have the functionality to allow customers to participate in product or service supply chain process design and to create a completely customized product or service according to customer preference. Customers involve in the supply chain process design by participating in activities of manufacturers or service providers upstream the supply chain. Therefore, the interactive system, interactive interface and interaction patterns among the organizations on this supply chain determine the supply chain efficiency. The internal efficiency and flexibility of the various organizations could be improved through their internal management. But the efficiency of coordination and communication between organizations will be determined by the efficiency of interaction system between two or more organizations.

Traditional interactive system in between organizations is a traditional transaction contract relationship. The interface of this system is mechanically integrated; the interactive model is cash on delivery. Despite of a periodic statement relationship, the interactive operation often has a clear boundary interface or demarcation point. This kind of interface integration approach and interactive operation is the black hole of efficiency loss of supply chain. The solution of this problem is that the related organizations create an organic and embedded-based integration pattern through strategic alliances. To well serve the common customers, the related organizations should develop a cooperation relationship tighter than the contractual trade relation, use an organic interface characterized by good design according to supply chain process but not the organization boundary, cut unnecessary operation procedures and improve the information exchange speed.

\subsection{Information support system}

Information support system is the nervous system of the railway freight transport mass customization marketing system. Without a perfect nervous system, the whole marketing system can not operate in accordance with the designed target. Because the essence of customized marketing system is that the service system can make a quick and accurate response to customer's needs and allow them to participate in the process of the design work and amend this demand at any time. If there is no good information support system, mass customization service is impossible to realize.

\section{Mass customization marketing strategy for China railway freight transport service}

Mass customization marketing strategy for railway freight transport service focuses on the following three issues: to determine the best range of customized services, to make resources intensification strategy and product strategy ensure sufficient customized demand for production system, to make informatization strategy ensure information communication for customized services.

\subsection{To provide differentiated and customized services to customers of different values}

To provide better service for customers is to get more benefits, short-term benefits or long-term strategic interests. But the provision of services consumes cost. Figure 1 shows an "S" relationship between revenue / profit and the level of service, which means that the provision of service of less than the minimum acceptable 
service level L ("service threshold") will lead to a negative profit, and that a service after this threshold level promises a positive profit, and that the maximum profit arrives at $\mathrm{S}$ point. At this point the marginal return of the service cost is maximal, but then if it continues to improve service levels, the return rate will still be positive until the $\mathrm{M}$ point where the marginal profit of service cost comes to zero and the total profit reaches maximum.

Mass customization marketing does not mean to provide customized services to all customers or all potential customers. It serves customers with priority based on different customer values. According to 80/20 rule, it may provide customized services to the A-class customers, while standardized service to B-class and C-class customers. Mass customization service means that the customized services may be expanded to all A and B classes of customers, as well as some potential C-class customers. Our research has shown that the customer concentration of China railway freight transport service reaches 90/02, that is, A-class and B-class customers together account for only $2 \%$ of the total number of customers, but they provide a source of $90 \%$ profit. This result shows that the customer concentration of China railway freight transport is higher than that of other general industries, and the concentration increases after the less-than-carload goods service stations are canceled. Based on these ideas, the customized service strategy for China railway freight transport is developed (shown in Figure 2).

According to China railway statistics from January to November in 2009, 180 clients among of 200,000 clients in total contributed $40 \%$ traffic volume to the total volume. The top 5 goods were coal, metal ores, iron and steel, petroleum and grains, which accounted for $73.8 \%$ of the total traffic volume. There is no doubt that these clients the railway's very important customers and these goods are very important products. However, in future, the goods adapt for container transport and the manufactured goods will be the fastest growing and with the greatest potential freight areas and they could become the railway's star products.

\subsection{Resource intensification strategy and product innovation strategy}

Customization marketing aims to improve service quality, to better meet customers' transportation needs, and to strengthen market development capabilities. Customization service requires that production and operation management system can realize its commitments to its customers.

From the appearance, customization, intensification and mass production are contradictory; in fact, they are not necessarily in a natural opposite relationship. Adjusting the layout of freight transport station, railway lines and less-than-carload business, the railway system will have to close services at those stations with low traffic demands and for the special railways, concentrate the freight transport business at the larger freight transport service centers, build loading and unloading site for through fully loaded cargo at those stations with given traffic volume. This business process-oriented resource allocation optimization makes high-level customization, and low-cost intensification and mass production become a concomitant relationship. If there is no intensive adjustment, it will be impossible to expand the scope of customization.

Freight transport production innovation strategy is mainly to achieve the goal of low cost and high efficiency in the framework of deeper customization. With enough capacity of production system, innovation in product design can further improve the efficiency of equipment utilization and the level or scope of customization. Railway freight transport production innovation mainly focuses on designing various types of new products (including through train for bulk goods, five scheduled train, baggage \& parcel train, container train, etc.) based on the volume and stability of transportation demands. In order to further strengthen the product customization ability, it also focuses on creating new product combination through strategic alliance with logistics providers in the end of supply chain and coordinators for combined transportation.

\subsection{Informatization strategy}

Railway freight information system is an important condition for mass customization of railway freight transport service. Information support systems should provide the following functions: allows for rapid implementation of information communication between railway service providers and their customers, considering the convenience for customer to issue a demand and to understand the processing progress and for the railway to understand customer's needs and the changes in timer and to gain time for quick response; reduces the distance between the railway and the customers, and expands the front service to the customer's hands; provides virtual business office with the basic functions of business entities and develops e-commerce to reduce transaction costs. Railway freight transport informatization strategy an indispensable condition for customization service. It uses modern internet technology and communication technology, it reduces the distance between the customers and the service providers and the forward logistics channels, reduces information delivery time, improves collaboration level of the organizations and improves the accuracy of information. 


\section{Conclusions}

From the analysis above, it could come to the conclusion that, whether it will be successful for China railway to implement customization marketing strategy on the freight transport service will depend on three functional strategies. Firstly, a VIP customer relationship management system needs to be built up and a more reasonable customer evaluation index system needs to be developed to evaluate customer's value instead of simply using traffic volume or freight transport revenue. Secondly, it needs to establish a production operation system which can make rapid responses to customer demand and ensure service quality, and design freight transport products to satisfy the market demand and play to the railway's technological advantages. Finally, a business process management information system needs to be established to help run e-commerce and directly get access to customer demand information through the interaction with customers, so that mass customization marketing strategy for railway freight transport can be carried out.

\section{References}

Cai Jianhua. (2006). On Flexibility of Lean Production System - from the Perspective of Resource Integration. Science and Technology Management Research, (7): 120-123

Don, P. Rogers, M., \& Dorf, B. (1999). Is your Company Ready for One-to-One Marketing? Harvard Business review, Jan.-Feb. 151-160

Dresner, Martin \& Xu, Kefeng. (1995). Customer Service, Customer Response, and Corporate Performance in the Service Sector. Journal of Business Logistics, 16(1): 23-40.

Fang, Xiaoping, Chen, Zhiya \& Li, Zhizhong. (2003). A Discussion on the Feasibility of Regular Rail Transport Carrying Container between Zhujiang Delta and Yantian Port. System Engineering, 21(2): 74-78.

Guo Yuhua. (2006). Strengthen Service Conception, Innovate Service Methods, Realize the Historical Breakthrough on Railway Freight Transportation Service. Railway Freight Transport, (3): 4-6

PINE, B. J. II. (1993). Mass Customization: The New Frontier in Business Competition. Boston: Harvard Business School Press.

Wen, Kexue \& Han, Boling. (2004). Speed up the Development of Professional Transportation; Build a First-Class Modern Logistics Enterprise. Railway Freight Transport, (5): 5-7

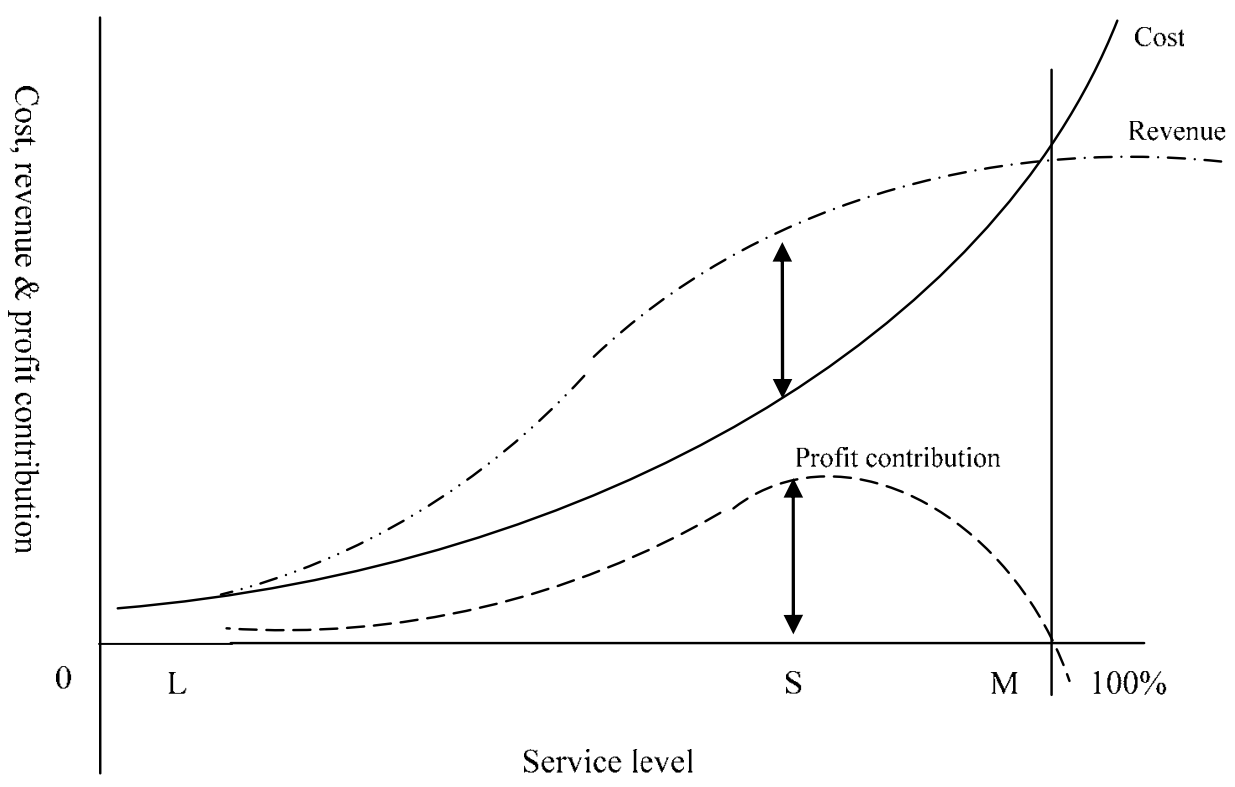

Figure 1 service cost、revenue/profit and service level 


\begin{tabular}{|c|c|c|c|}
\cline { 2 - 4 } & $\begin{array}{c}\text { Very important customers } \\
\text { Very important products } \\
\text { Complete customization }\end{array}$ & $\begin{array}{c}\text { Important customers } \\
\text { Very important products } \\
\text { Complete customization }\end{array}$ & Limited customization \\
\cline { 2 - 5 } & $\begin{array}{c}\text { Very important customers } \\
\text { Important products } \\
\text { Complete customization }\end{array}$ & $\begin{array}{c}\text { Important customers } \\
\text { Important products } \\
\text { Limited customization }\end{array}$ & $\begin{array}{c}\text { Standard products } \\
\text { Develop potential customer }\end{array}$ \\
\cline { 2 - 4 } & $\begin{array}{c}\text { Standard products } \\
\text { Limited customization }\end{array}$ & Develop potential customer \\
A & \multicolumn{2}{c}{ Customers }
\end{tabular}

Figure 2 customization service and important customers, important products 